Energy Systems Environmental Restoration Program

K-25 Site Environmental Restoration Program

\title{
Electromagnetic Survey of the K1070A Burial Ground at the Oak Ridge K-25 Site, Oak Ridge, Tennessee
}

\author{
J. E. Nyquist \\ M. S. Emery
}

Date Issued-January 1993

Prepared by

Environmental Sciences Division

Oak Ridge National Laboratory

ESD Publication 3988

Prepared for

U.S. Department of Energy

Office of Environmental Restoration and Waste Management

under budget and reporting code EW 20

OAK RIDGE K-25 SITE

Oak Ridge, Tennessee 37831-7256

managed by

MARTIN MARIETTA ENERGY SYSTEMS, INC.

for the

U.S. DEPARTMENT OF ENERGY

under contract DE-AC05-84OR21400 


\section{Author Affiliations}

J. E. Nyquist is a member of the Environmental Sciences Division, and M. S. Emery is a member of the Instrumentation and Controls Division. Both divisions are part of Oak Ridge National Laboratory, Martin Marietta Energy, Systems, Inc.

\footnotetext{
+* $\div-4=0$
} 


\section{CONTENTS}

FIGURES $\ldots \ldots \ldots \ldots \ldots \ldots \ldots \ldots \ldots \ldots \ldots \ldots \ldots \ldots \ldots \ldots \ldots$

EXECUTTVE SUMMARY $\ldots \ldots \ldots \ldots \ldots \ldots \ldots \ldots \ldots \ldots \ldots \ldots \ldots$ vii

1. INTRODUCTION $\ldots \ldots \ldots \ldots \ldots \ldots \ldots \ldots \ldots \ldots \ldots \ldots \ldots \ldots \ldots$

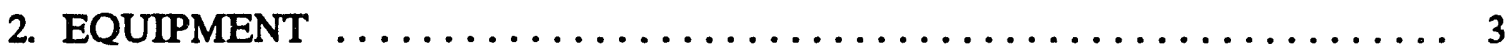

2.1 EM31 TERRAIN CONDUCTIVITY METER $\ldots \ldots \ldots \ldots \ldots \ldots \ldots \ldots \ldots, 3$

2.2 INTERPRETATION OF THE EM31 DATA $\ldots \ldots \ldots \ldots \ldots \ldots \ldots \ldots \ldots . \ldots$

2.3 ULTRASONIC RANGING AND DATA SYSTEM $\ldots \ldots \ldots \ldots \ldots \ldots \ldots 6$

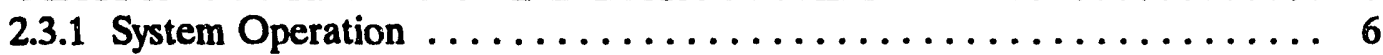

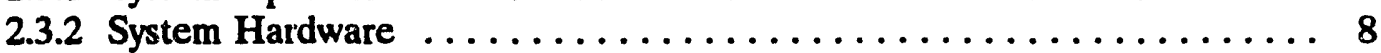

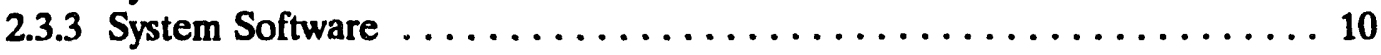

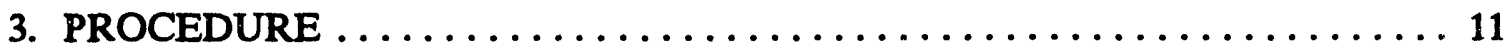

3.1 GENERAL PROCEDURE . . . . . . . . . . . . . . . . 11

3.2 DATA COLLECTION AT THE K1070A BURIAL GROUND . . . . . . 13

4. RESULTS AND DISCUSSION $\ldots \ldots \ldots \ldots \ldots \ldots \ldots \ldots \ldots \ldots \ldots \ldots \ldots$

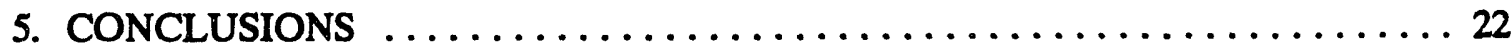

5.1 BURIAL GROUND BOUNDARIES AND WELL DRILLING . . . . . 22

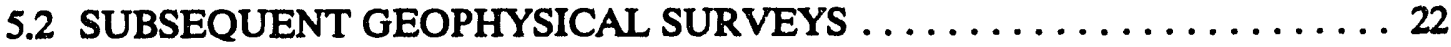

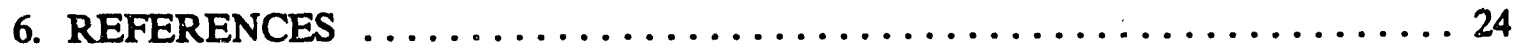

Appendix. EXPLANATION OF DATA PROVIDED ON MAGNETIC MEDIA $\ldots 26$ 


\section{FIGURES}

1 Map of the K1070A burial ground showing soil sampling points,

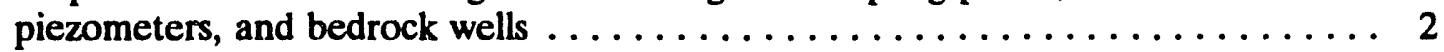

2 Operating principle of a terrain conductivity meter $\ldots \ldots \ldots \ldots \ldots \ldots$

3 EM31 responses to simple and to complicated terrains $\ldots \ldots \ldots \ldots \ldots \ldots$

4 USRADS using ultrasonics to locate the surveyor $\ldots \ldots \ldots \ldots \ldots \ldots \ldots$

5 Hardware for the USRADS/EM31 system $\ldots \ldots \ldots \ldots \ldots \ldots \ldots \ldots \ldots$

6 One of the authors (Jon Nyquist) using USRADS to collect data at Solid Waste Storage Area 4 at ORNL ................... 12

7 Northeast-southwest track map of the K1070A burial ground .......... 14

8 Northwest-southeast track map of the K1070A burial ground $\ldots \ldots \ldots \ldots \ldots 15$

9 Track map of the K1070A burial ground made without the EM31 to delineate features to aid subsequent EM31 data interpretation $\ldots \ldots \ldots \ldots \ldots$

10 Gray-scale contours of the quadrature data based on the northeast-southwest profiles

11 Gray-scale contours of the inphase data based on the northeast-southwest profiles

12 Gray-scale contours of the quadrature data based on the northwest-southeast profiles

13 Gray-scale contours of the inphase data based on the northwest-southeast profiles

14 The contours of the quadrature data based on the northwest-southeast profiles (Fig. 12) superimposed on the site map 


\section{EXECUTIVE SUMMARY}

The K1070A burial ground, located at the K-25 Site on the Oak Ridge Reservation, received chemical and radioactive wastes from the late 1940s until 1975. Analysis of water samples collected from nearby monitoring wells indicates that contamination is migrating offsite.

In November 1991, Oak Ridge National Laboratory (ORNL) personnel collected highresolution electrical terrain conductivity data at the K1070A burial ground. A Model EM31 terrain conductivity meter manufactured by Geonics Limited was used in conjunction with the ORNL-developed Ultrasonic Ranging and Data System (USRADS) to perform the survey. The purpose of the survey was to provide Environmental Restoration (ER) staff with a detailed map of the spatial variation of the apparent electrical conductivity of the shallow subsurface (upper $3 \mathrm{~m}$ ) to assist them in siting future monitoring wells closer to the waste area without drilling into the buried waste.

Because trench fill has different electric properties than undisturbed soil and because much of the waste was buried in metal canisters, variations in the electrical conductivity of the ground could be used to delineate the burial area. The anomalous conductivity areas mapped by the ORNL team at the K1070A burial ground generally coincide with the locations of the waste pits and trenches shown on the burial plans. Only at one section along the southern boundary does the region of anomalous conductivity extend beyond the mapped burial area boundary. The full extent of this anomaly could not be mapped because it was too densely wooded to permit access with the EM31.

The terrain conductivity anomaly boundaries are abrupt, making it relatively easy to delineate the waste areas. Therefore, it should be possible to drill monitoring wells safely within 10-20 ft of the waste areas. Attempting to place wells between individual trenches based on the terrain conductivity data, however, would risk drilling into buried waste material. It is possible for a waste canister to go undetected if (1) the waste is buried below the detection limit of the instrument, (2) the canister is too small to detect, or (3) the survey lines are spaced too widely and the canisters between the survey lines are beyond the sensor range. We addressed each of these concerns in designing the survey. The records indicate that the waste at the K1070A burial ground was not buried deeply, so the 3-m depth detection limit of the EM31 should be adequate. Because the waste was buried in trenches, the cumulative anomaly of many small canisters should be easily detectable. Finally, we used the USRADS automatic locating and data logging system to enable us to collect terrain conductivity data on tightly spaced survey lines with average separations between measurement points along line of about $0.5 \mathrm{~m}$ with line separations of about $5-8 \mathrm{~m}$. In addition, we collected two perpendicular sets of traverses, the first running northwest-southeast and the second running northeast-southwest, providing double coverage of the entire site. 


\section{INTRODUCTION}

On November 5-6, 1991, the authors performed a terrain conductivity survey of the K1070A burial ground at the Oak Ridge K-25 Site. We used a Model EM31 terrain condictivity meter manufactured by Geonics Limited, Mississauga, Ontario, Canada, and an Ultrasonic Ranging and Data System (USRADS) developed at Oak Ridge National Laboratory (ORNL). The plans of the K1070A burial ground show three waste pits and five trenches. Although a number of piezometers have been drilled and soil samples have been collected and analyzed along the perimeter of the burial ground (Fig. 1), Environmental Restoration (ER) personnel at the K-25 Site wanted to place additional monitoring wells closer to the burial area while minimizing the risk of drilling into a waste canister.

The purpose of this survey was to provide ER staff with a detailed map of the spatial variation of apparent electrical conductivity of the burial ground. Apparent electrical conductivity is the electrical conductivity of the ground that would produce a measured instrument reading if the ground had a single, uniform electrical conductivity. When the ground in the vicinity of the terrain conductivity meter is inhomogeneous, apparent conductivity is a weighted average of the conductivities of the different materials within the sensing range of the instrument. Because trench fill has different electrical properties than those of undisturbed soil and because much of the waste was buried in metal canisters, variations in the apparent electrical conductivity of the ground occur both where the natural soil has been replaced with fill material and where metallic objects are buried. Apparent conductivity maps, therefore, can be used to determine whether the burial records on file are reasonably accurate by delineating regions with anomalous conductivity values. By selecting well locations close to, but outside of, regions of anomalous conductivity, it is possible to place monitoring wells close to the buried waste boundaries but with minimal chance of drilling into a waste canister. 


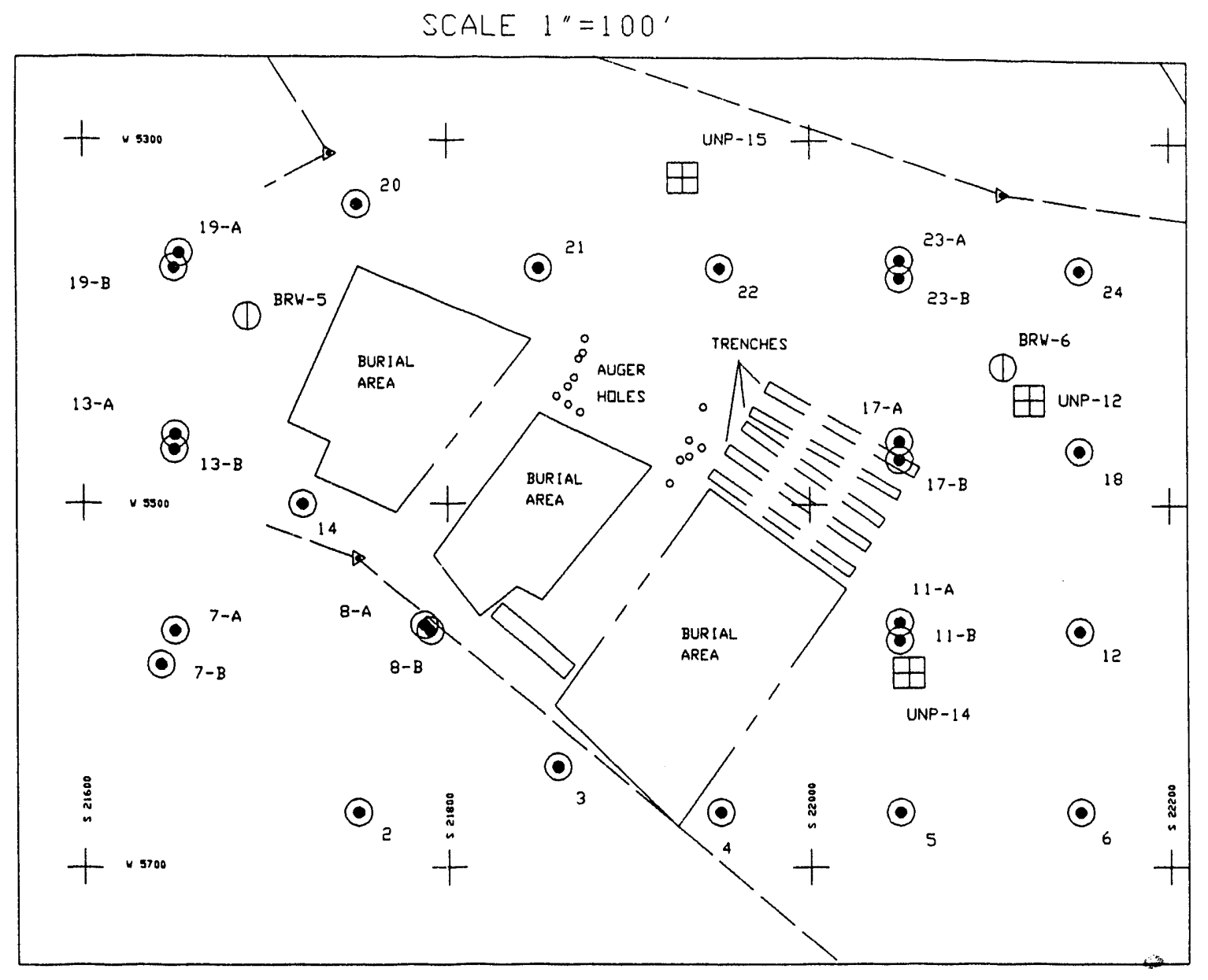
- Soil sampling point
田 piezameter
(1) BEDROCK WELL

Fig. 1. Map of the K1070A burial ground showing soil sampling points, piezometers, and bedrock wells. 


\section{EQUIPMENT}

\subsection{EM31 TERRANN CONDUCTIVITY METER}

We measured the apparent electrical conductivity at the K1070A burial ground through the use of a Geonics Limited EM31. The EM31 consists of an instrument box which is attached to a shoulder harness and is centered on a PVC boom that maintains a fixed separation and relative orientation between a transmitter coil at one end of the boom and a receiver coil at the other end. The transmitter broadcasts an alternating electromagnetic field $(9.8 \mathrm{kHz})$ that induces electrical eddy currents in the ground (Fig. 2). The receiver detects both the primary field generated by the transmitter and a secondary field generated by eddy currents induced in the earth by the primary field. These eddy currents create an alternating magnetic field of the same frequency as the transmitted wave but shifted in phase and reduced in amplitude. The depth of the induced eddy currents, and hence the survey depth, is controlled by the spacing between the transmitter and the receiver coils. For the EM31, the coil separation is fixed at $3.66 \mathrm{~m}$, limiting the maximum sensing depth to about $3 \mathrm{~m}$. The EM31 responds to anything that changes the average conductance of the ground-for example, buried metal, soil moisture, clay content of the soil, and chemicals in the groundwater such as salts and metal ions (Geonics Limited 1984).

\section{INTERPRETATION OF THE EM31 DATA}

The interpretation of EM31 data is straightforward when the ground is homogeneous. The magnetic field of the induced eddy currents is the vector sum of a component in phase with the transmitted wave and a component 90 degrees out of phase with the transmitted wave, called the quadrature component, which is similar to the resolution of a position vector into $x$ and $y$ components. The EM31 measures both components, and the current induced in the ground is proportional to the electrical conductivity of the ground. For a homogeneous earth (or it least homogeneous in the top $3 \mathrm{~m}$, the approximate penetration depth of the EM31 signal), the amplitude of the quadrature component of the magnetic field produced by these eddy currents relative to the transmitter strength is directly proportional to the electrical conductivity of the ground. The instrument can then be calibrated to report the electrical conductivity of the ground directly in millimhos per meter (Geonics Limited 1984; McNeill 1980a, 1980b).

When the terrain is complex (e.g., buried steel drums are scattered throughout a landfill), the EM31 still reports the quadrature component in millimhos per meter, but this is only the apparent electrical conductivity, not the true electrical conductivity of the ground, or the drums, or a simple average conductivity. The magnitude of the anomaly depends on its size, position, shape, and electrical conductivity of all buried objects; it is impossible to determine all four from EM31 readings alone. A given anomaly, for example, might be created by a cluster of buried 55-gal drums, an old desk, or some metal scrap (Fig. 3). For certain sourcereceiver-object geometries, the presence of buried metal can even reduce the apparent electrical conductivity, producing an anomalous low. In some cases, calculations can be made

on a case-by-case basis by using the width and the amplitude of the anomaly to determine if a particular anomaly is too large to have been produced by, say, a single drum. In general, 


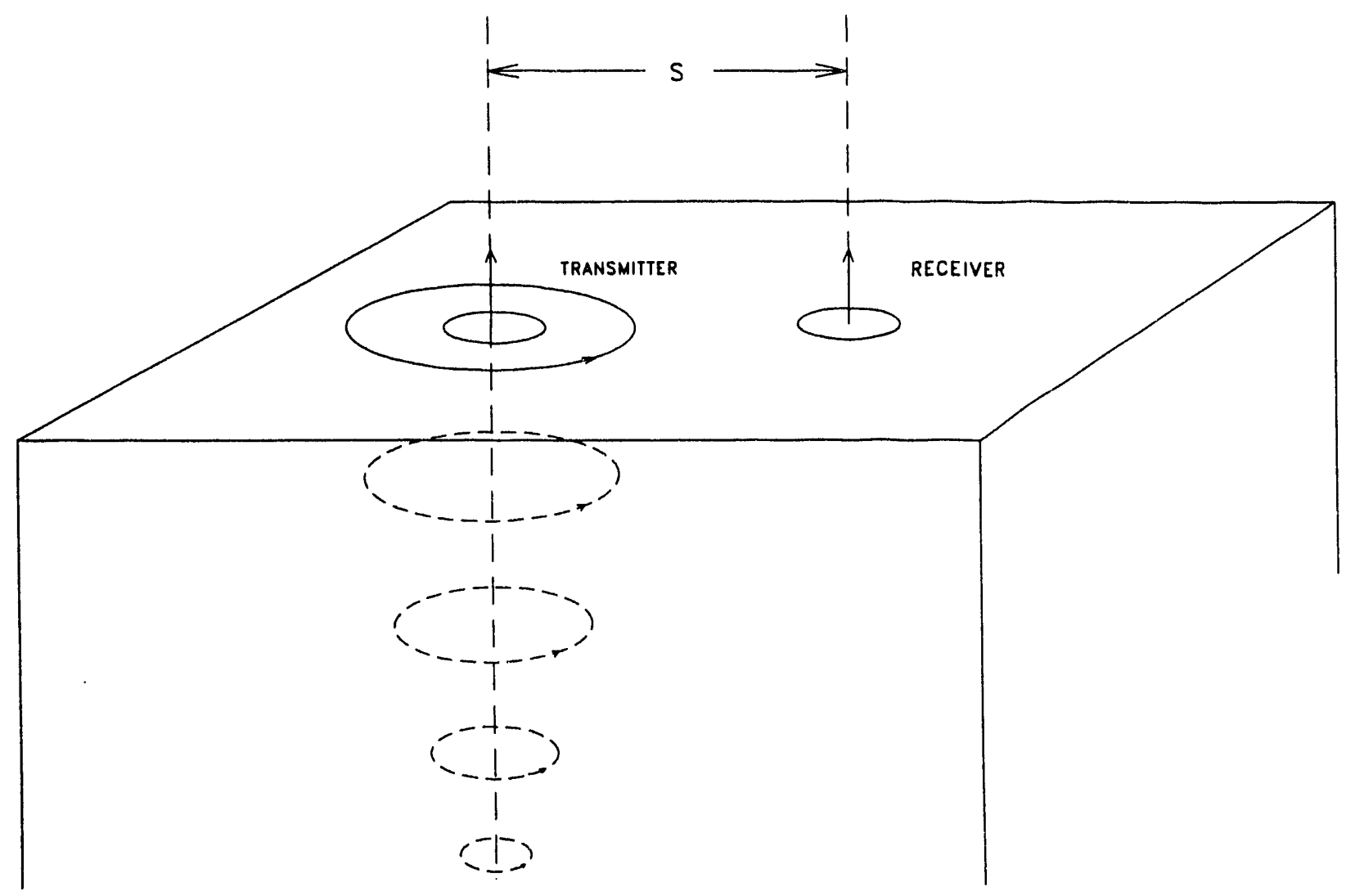

Fig. 2. Operating principle of a terrain conductivity meter. A transmitter coil broadcasts an electromagnetic field. This field induces eddy currents in the ground which create a secondary electromagnetic field. The receiver measures the ratio of the field from the transmitter to the secondary field and converts this to apparent electrical conductivity. 
MAPPING SQIL THICKNESS

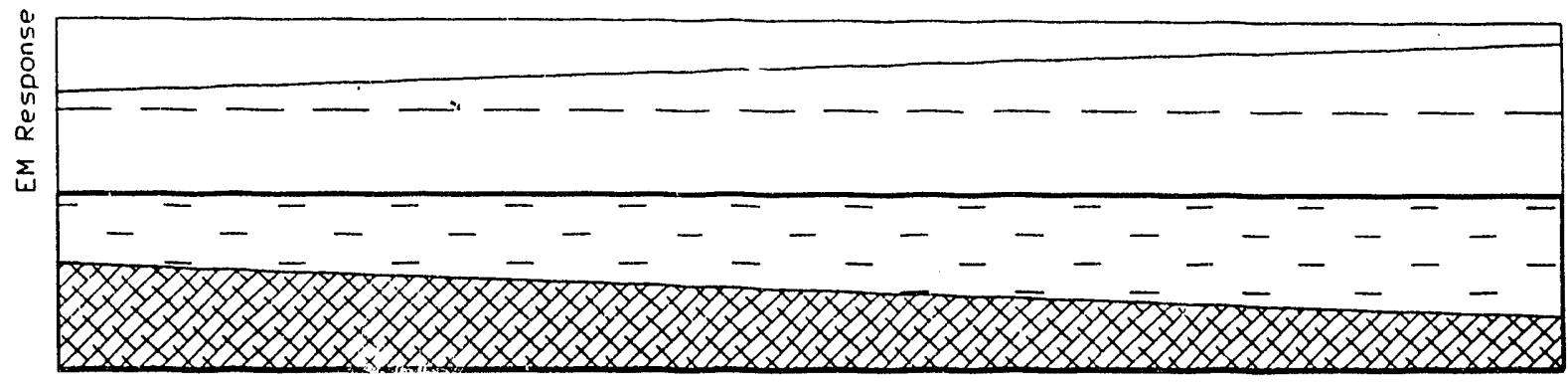

MAPPING BURIED QBJECTS

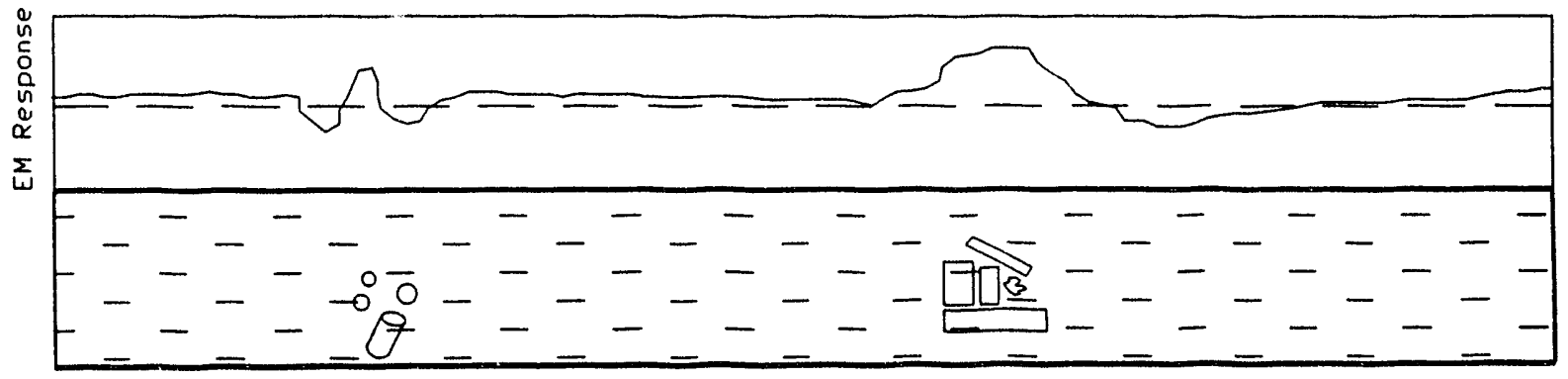

Fig. 3. EM31 responses to simple and to complicated terrains. EM31 response is easy to interpret in simple terrain where it can be used, for example, to map soil thickness when the electrical conductivities of the soil and bedrock are known. In complicated terrain, or when there are buried metal objects, the instrument response is useful qualitatively, but that response alone is insufficient to determine size, depth, orientation, and electrical conductivity jointly. 
EM31 data, especially for a region as heterogeneous as a landfill, can be interpreted only qualitatively. Therefore, interpretation of apparent conductivity data in complex areas is often limited to contouring or profiling the measurements while noting the presence or absence of anomalous values (departures from background) unless secondary information such as burial plans or other types of geophysical data are available.

In qualitative analysis of EM31 measurements, the inphase data can be useful as well. The disadvantage of inphase data for mapping soil conductivity is that the inphase response plotted against electrical conductivity is not a simple linear relationship, whereas the quadrature response is linear, but the inphase signal over buried metal is often stronger than the quadrature signal (McNeill 1983). USRADS, discussed later, automatically records both the inphase and the quadrature signals at each measurement point.

The limitations of electrical conductivity data interpretation determine the type of questions that can be answered with EM31. It is unreasonable to expect an EM31 survey to produce an inventory of buried objects. A more reasonable expectation is that the apparent conductivity data may be used to locate buried waste and to delineate its boundaries but probably not its depth. It is fair to say that the more data, the better. Tightly spaced measurements outline the anomaly boundaries sharply and guarantee that no conductive object is missed, but this slows data collection and analysis. Tightly spaced measurements also require more survey preparation because the measurement grid will take longer to mark out, particularly for a multiple-acre site. Because the EM31 is an analog instrument without a built-in data recording system, time is lost as both the surveyor's position and the instrument's reading must be recorded in a field notebook, or recorded with an electronic data logger and later transferred to a computer for analysis. Generally, a compromise must be made between time and money on the one hand, and survey quality on the other. USRADS overcomes these difficulties by recording the EM31's position and reading automatically, without a preset grid, and by storing the data directly on a portable computer.

For additional information on electromagnetic survey interpretation, see Telford et al. (1990) and Frischknecht et al. (1991).

\subsection{ULTRASONIC RANGING AND DATA SYSTEM}

As part of the Department of Energy's Uranium Mill Tailings Remedial Action Project (UMTRAP), ORNL was requested to survey, in 3 years, 8000 properties where the presence of uranium mill tailings is suspected. To save time and money, ORNL developed the USRADS technology to automate much of the survey process and to provide tabular and graphical data that could be displayed in the field or used in the office for report generation. We have adapted the system to work with the EM31, collecting both the quadrature and inphase data simultaneously (Nyquist and Blair 1991).

\subsubsection{System Operation}

The system setup takes only about $30 \mathrm{~min}$ for a 1 -acre site. Stationary receivers are placed on the property so that the surveyor is in view of at least three of the stationary receivers from any location on the property (Fig. 4). Once the stationary receivers have been placed on the property, the speed of sound is measured and the locations of the stationary 
ORNL-OWG 86-7161

LOCATING THE SURVEYOR BY TRIANGULATION

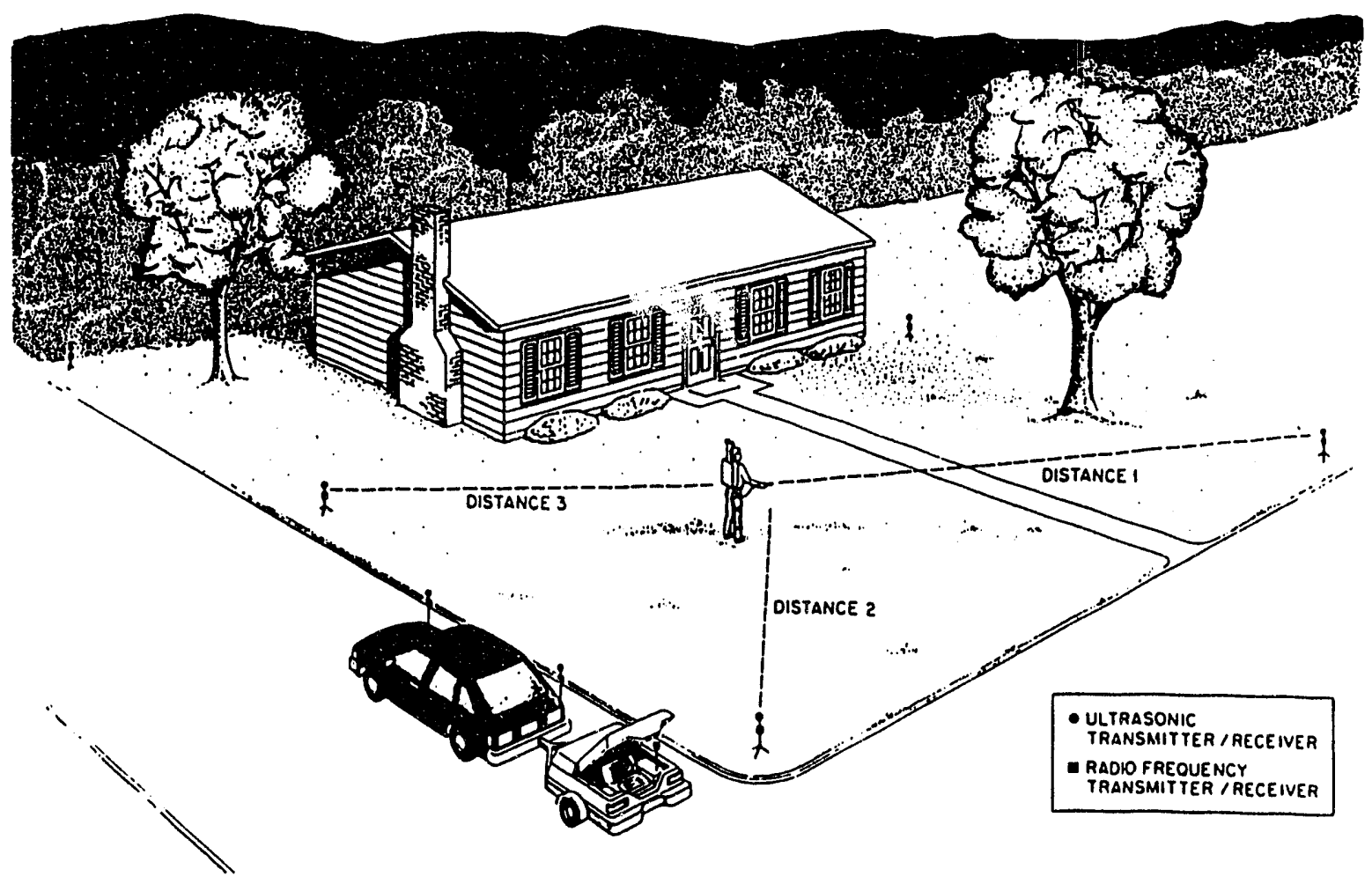

Fig. 4. USRADS using ultrasonics to locate the surveyor. 
receivers are computed. A minimum of two people are required to operate USRADS. One walks the property with the geophysical instrume ${ }_{i .}$. while his position and instrument's readings are automatically recorded by the USRAD system; the other operates a portable computer that analyzes the data they come in and tells the surveyor by radio where additional coverage is needed.

Preliminary analysis of the data in the field is a major advantage of USRADS over conventional geophysical surveys. As the surveyor walks the property, an ultrasonic crystal in the surveyor's backpack is pulsed each second and the data from the survey instrument are transmitted to the computer by radio. Each second, the computer reads the time-of-flight data from stationary receivers, triangulates the surveyor's location, plots the surveyor's location on the computer screen, and stores all raw data. By plotting the surveyor's location each second, the computer operator can view the surveyor's coverage of the property at any time during the survey. In addition to plotting the surveyor location, the computer highlights any data point that exceeds a threshold entered by the operator, so that any areas of concern are identified on the display, which helps ensure that sufficient data have been obtained to characterize an area.

\subsection{System Hardware}

USRADS consists of a surveyor's backpack, 15 stationary receivers, a master receiver, * custom computer interface and counter timer module, a personal computer, and a small trailer or a van to transport this equipment (Fig. 5).

The backpack contains the interface circuitry to receive the signal from the field instrument (the EM31 terrain conductivity meter), an ultrasonic transmitter, and radio frequency equipment to establish a bidirectional communication link with a computer mounted in the trailer. The ultrasonic transmitter is a lead-zirconate-titanate crystal that is in the form of a circular cylinder with a hollow core. The crystal has a diameter of $2.2 \mathrm{in}$. and a height of 1.445 in. This crystalline material and its dimensions result in a natural resonating frequency of $19.5 \mathrm{kHz}$. The crystal is pulsed for $10 \mathrm{~ms}$ each second as the data from the portable survey instrument are transmitted to the computer via the radio telemetry link. If the computer detects any problems, either with the data or in determining the surveyor's location, a message is transmitted to the surveyor and displayed on the handheld terminal to alert the surveyor of the malfunction. The backpack can be operated for a normal 8-h day from a rechargeable gel-cell.

The stationary receivers contain an ultrasonic receiver and a radio transmitter. The dimensions of the metal box that houses the ultrasonic receiver card, transmitter card, and rechargeable gel-cell battery pack are $10 \times 10 \times 15 \mathrm{~cm}$. Each stationary receiver has a unique radio frequency so that the master receiver can identify which stationary receivers heard an ultrasonic signal. The master receiver therefore contains 15 radio receivers, one for each stationary receiver, and a receiver and transmitter for communication with the backpack. Both the master receiver and the computer are powered by a gasoline-operated generator also carried in the trailer. 


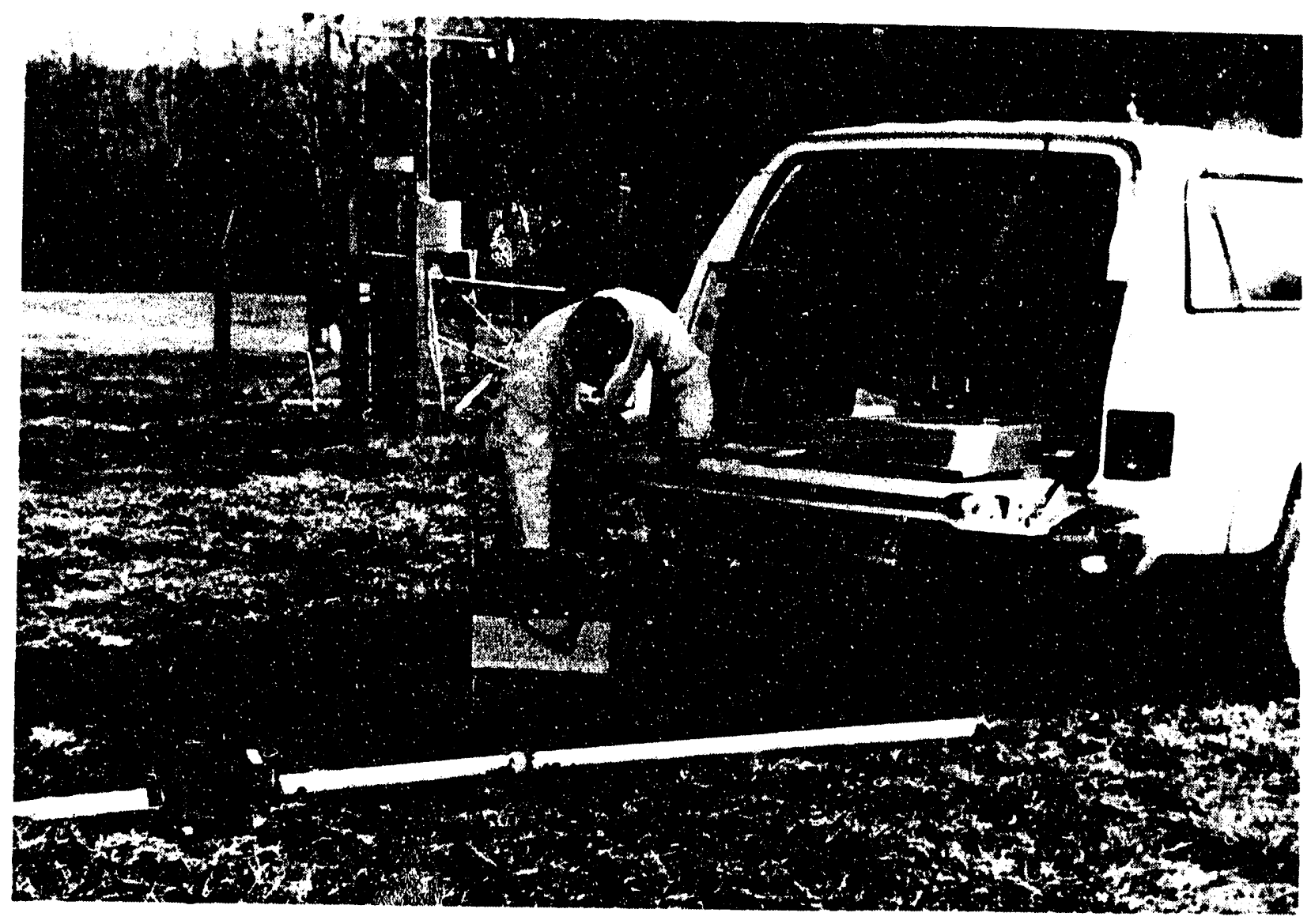

Fig. 5. Hardware for the USRADS/EM31 system. Included are a Compaq Portable II computer, master receiver, stationary receivers (on truck tailgate), backpack and handheld terminal (being adjusted), and EM31 terrain conductivity meter (on ground). 


\subsubsection{System Software}

Prior to the survey, a digitized schematic drawing of the property can be stored in the computer using AutoCAD. The property schematic is displayed on the computer's monitor, and the survey data are added to this information. As the surveyor traverses the property, his past and present positions are displayed to denote the completeness of coverage by the surveyor. During the survey, the software checks incoming information and alerts the surveyor (through the backsark terminal) if errors are detected either in the survey data or in the position data. To susure data integrity, all data are stored on the hard disk every $30 \mathrm{~s}$.

On-site data reduction is accomplished by several software packages. USRADS enables the surveyor to analyze the survey data to ensure that sufficient data to characterize the property are obtained before leaving the site. The surveyor can view the data in a number of graphical formats and can also obtain summary reports. The graphical formats of the data supported by USRADS are Replay, Block Statistics, Contour, and 3-D Plots. The Replay program will generate the same display that the surveyor viewed when the survey of the property was completed. The data are replayed in the same order as the data were taken. The Block Statistics routine enables the operator to select a grid block size and have the data analyzed for each block. If the mean of the data for a particular grid block is greater than the operator-entered threshold, then that block is highlighted on the monitor, and the statistical information for that grid block is stored in the summary report. Raw data are converted to appropriate units and displayed or printed in tabular or graphical form. By indicating preset thresholds, areas of contamination can be identified and vital statistics can be calculated (e.g., area size, number of measurements, measurement range, average, and standard deviation). The Contour routine generates a summary report and outlines the areas that exceeded the user input threshold. The 3-D Plot routine generates two different views of the data and provides a means by which the surveyor can view all of the data obtained during the survey. Information displayed in the field is output directly into a report-ready format. 


\section{PROCEDURE}

\subsection{GENERAL PROCEDURE}

The data collection procedure using the EM31 and USRADS is descritued in the Procedure Manual written by the Chemrad Tennessee Corporation, Oak Ridge, Tennessee. The following is a brief summary.

1. The EM31 is taken through the battery check and calibration check procedures described in the manufacturer's operations manual.

2. The EM31 is connected to the USRADS backpack and the USRADS program CHECK EQUIPMENT is run to verify that the USRADS backpack is functioning correctly, ensuring that the EM31 instrument reading is the same as the reading being logged by the computer.

3. Before the EM31 operator can begin surveying, the stationary receivers that pick up the ultrasonic pulse from the backpack must be deployed. Because system setup takes about $30 \mathrm{~min}$, when surveying a multiple-acre site it is normal to space the receivers to provide coverage over as large an area as possible. The rule of thumb is to position the receivers so that the surveyor will always be within $200 \mathrm{ft}$ of at least two of them. With the USRADS system up to 15 receivers can be deployed, so a single setup can provide coverage of several acres.

4. The distance between two of the stationary receivers is measured with a tape measure. This distance is used to compute the local speed of sound (a function of temperature and atmospheric pressure) and is the baseline used to scale all subsequent distance calculations. If there are any benchmarks such as surveyor stakes, wells, or signposts, then a stationary receiver is placed over the benchmark so that the USRADS coordinates (all computed relative to the two baseline stationary receivers) can later be translated and rotated to agree with the K-25 Site grid coordinate system.

5. The USRADS backpack is connected to a special ultrasonic crystal assembly called the "top hat" which is placed in turn on each of the stationary receivers and pulsed for $30 \mathrm{~s}$. While the top hat is on one receiver, the USRADS computer records the ultrasonic travel time to all the other receivers. In this fashion a matrix of interreceiver travel times is constructed, which, by using the baseline calibration distance, is converted into receiver locations by the computer.

6. Once the stationary receivers' positions have been established, the EM31 is connected to the backpack and one person walks the site with the EM31 (Fig. 6) while the other monitors his position and instrument readings as they are displayed in real time on the computer monitors.

7. Finally, the EM31 is disconnected and the backpack operator walks the perimeter of objects (e.g., wells, fences, and buildings) whose location is important for data interpretation or which might assist in establishing survey boundaries (e.g., roads, telephone poles, and streams). 


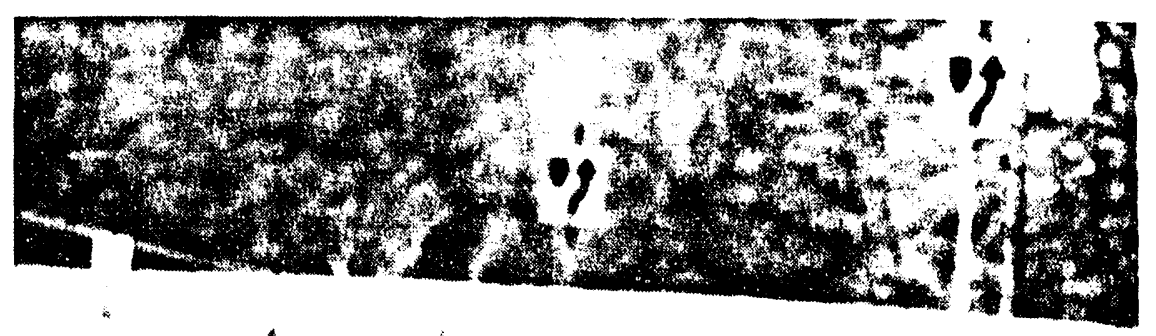

$|-|-1$
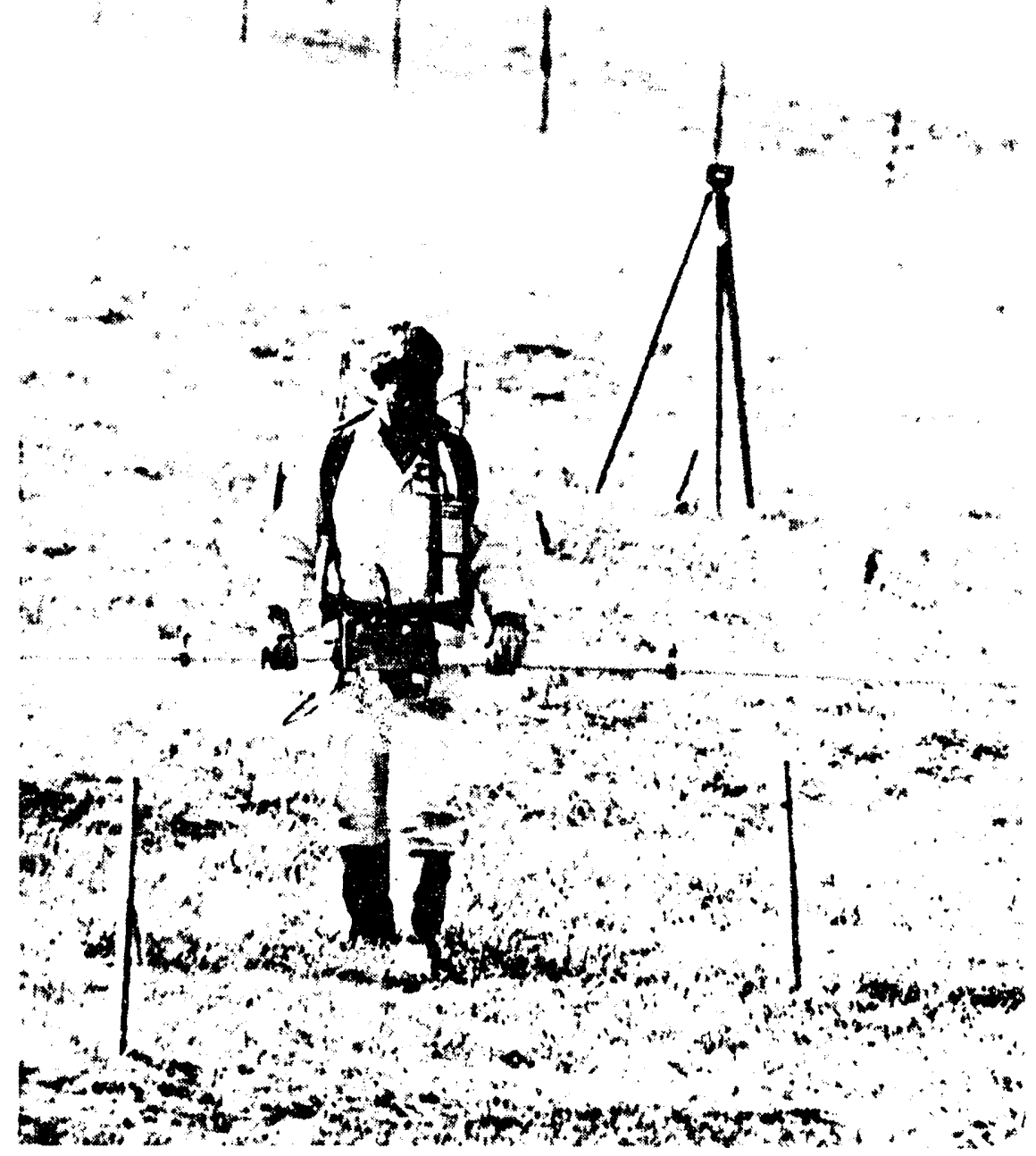

Fig. 6. One of the authors (Jon Nyquist) using USRADS to collect data at Solid Waste Storage Area 4 at ORNL. Notice the stationary receiver mounted on the tripod in the background. 


\subsection{DATA COLLECTION AT THE K1070A BURIAL GROUND}

The plan of the K1070A burial ground shows three waste pits and five trenches. Three setups were used to cover the K1070A burial ground, and six data files were generated: blocks A, C, and E contain the EM31 data, whereas blocks B, D, and F contain object locations as described in Step 7 above. The track maps (Figs. 7 and 8) show the locations of the EM31 measurement points. The surveyor's path meanders slightly, a consequence of trying to walk a rectangular grid with sparse survey markers. The coverage is so dense, however, that there are no large data gaps.

Data were collected with the EM31 boom set in vertical dipole mode with the instrument suspended approximately $1 \mathrm{~m}$ above the ground. The boom was oriented perpendicular to the operator's walking path (broadside).

Before the terrain conductivity work began, surveyors placed wooden stakes on a 100 -ft grid separation. Stationary receivers were located over these stakes whenever possible so that coordinates from the USRADS baseline receivers could be more easily translated to K-25 Site grid coordinates. Thus the stake positions were recorded in the local coordinate system used by USRADS during the surveys and were used to translate and rotate the data blocks into K-25 Site grid coordinates as part of the data processing.

The sharpest peak results when terrain conductivity data are collected along a traverse perpendicular to the trench axis. When the orientation of the trenches is not known in advance, it is prudent to collect two perpendicular data sets. At K1070A we collected data along northwest-southeast (Fig. 7) and northeast-southwest (Fig. 8) walking paths, parallel and perpendicular to the trenches as shown on the burial ground plans.

As described in Step 7 above, we used USRADS to map features useful for data interpretation, including piezometers, metal stovepipes protruding from the ground, the auger hole area, and the nearby dirt road (Fig. 9). 


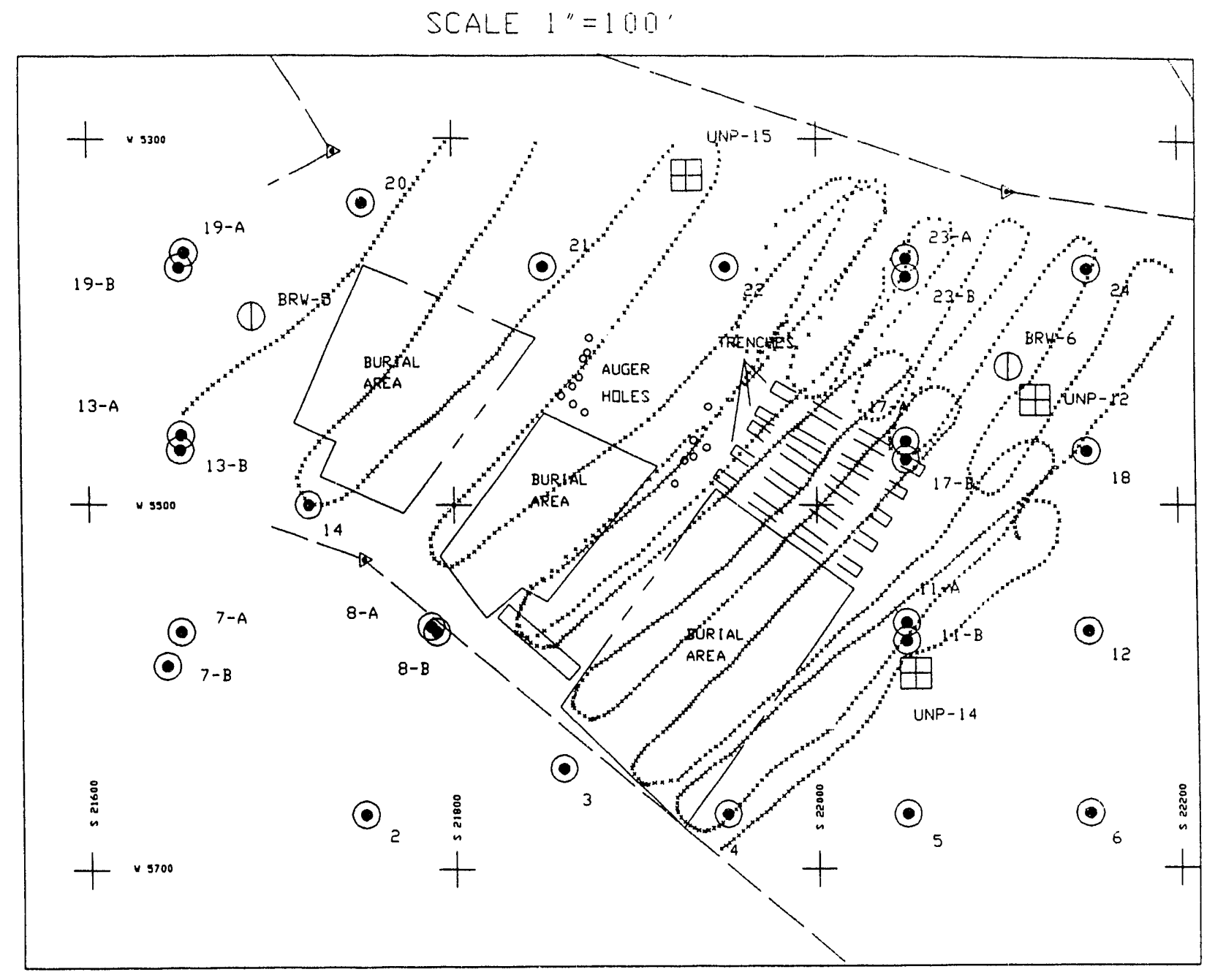
- soil sampling juint
円 PiezaMeTER
(1) BEDROCK WELL

Fig. 7. Northeast-southwest track map of the K1070A burial ground. Each " $x$ " is a measurement point. 
SCALE $\quad 1 "=100$

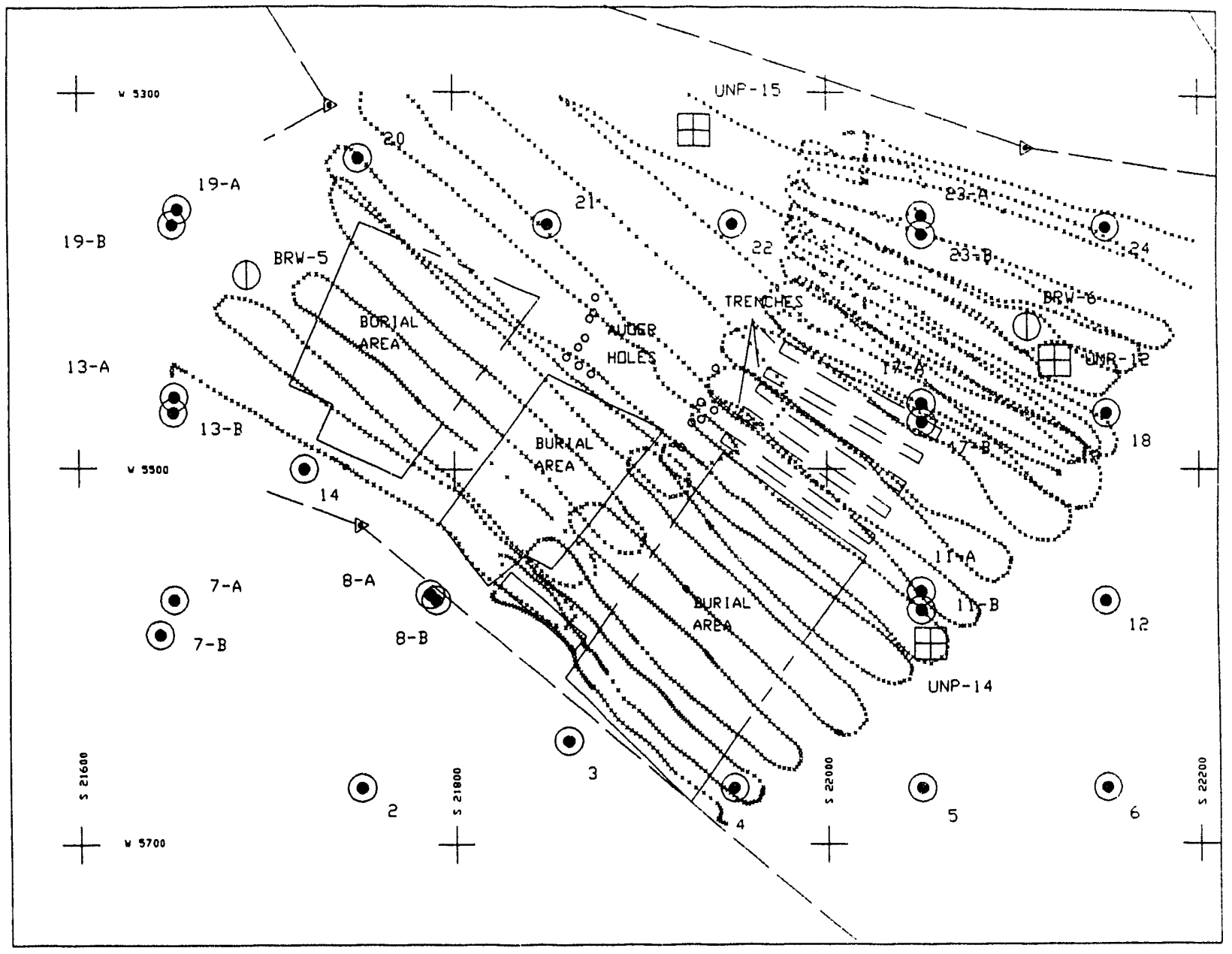

- suil sampling puint

PIEZDMETER

(1) BEDRTCK WELL

Fig. 8. Northwest-southeast track map of the K1070A burial ground. Each " $x$ " is a measurement point. 
SCALE $1 "=100$

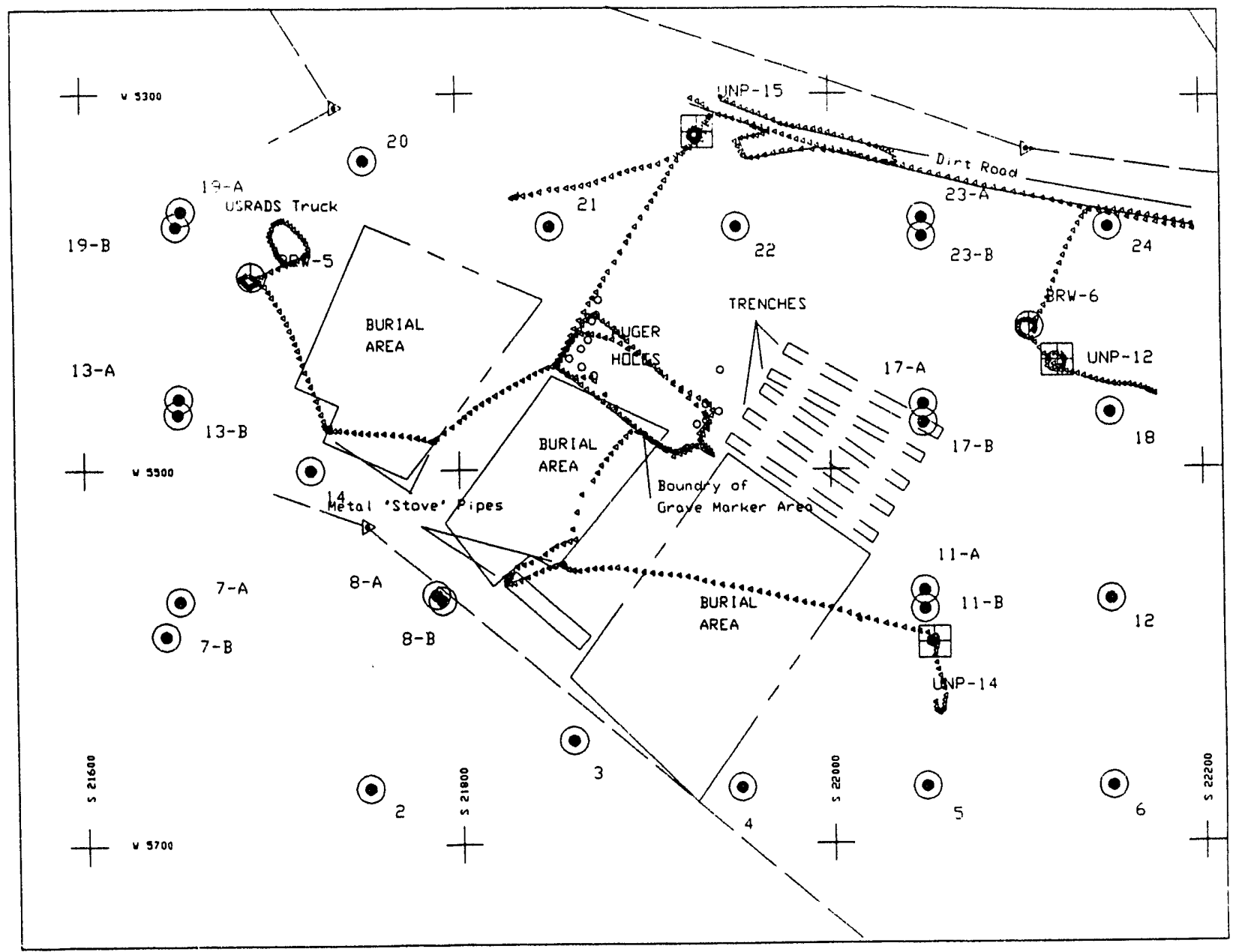

- soil sampling point

$\bigoplus$ PIEZTMETER

(1) BEDROCK WELL

Fig. 9. Track map of the K1070A burial ground made without the EMB1 to delineate features to aid subsequent EM31 data interpretation. 


\section{RESULTS AND DISCUSSION}

The data from the two perpendicular traverse directions were interpolated separately on to a rectangular grid (5-ft spacing) and contoured with the program Surfer (Golden Software), using a kriging algorithm to perform the interpolation and assuming a linear variogram. The grid cells were "blanked" when no data point was within the search radius of $20 \mathrm{ft}$ (the contours do not extend into blanked areas). Usually the choice of interpolation algorithm has a strong effect on the interpolation values, but with USRADS the data coverage is so tight and the interpolation distances are so small (generally $5 \mathrm{ft}$ or less) that kriging, inverse distance squared, and even linear interpolation all yield similar contours.

At the K1070A burial ground, the inphase and quadrature data correlated well, and both show anomalous boundaries that agree well with drawings showing the locations of the waste areas (Figs. 10-13). The exception is the region at roughly W5500, S21900. Although the drawings show a burial pit, the terrain conductivity anomaly is relatively weak. Apparently, there was not much metal buried in that pit, or perhaps it was buried deeper. Also note that the terrain conductivity anomalies extend beyond the mapped pit boundaries to the northwest. We measured anomalous terrain conductivity response to the edge of the cleared area.

Plots of both the quadrature and inphase data show a wide distribution of anomaly size and shapes-not surprising for a burial ground. There is probably a slight difference between the electrical conductivity of the burial ground backfill soil and the surrounding undisturbed soil, but undoubtedly all of the anomalies greater than a few millimhos per meter (quadrature data) or a few parts per thousand (inphase data) were created by buried metal objects. It is important to remember that the EM31's signal falls off fairly rapidly with depth; as a rule of thumb, only objects in the top $18 \mathrm{ft}$ will be detected. 


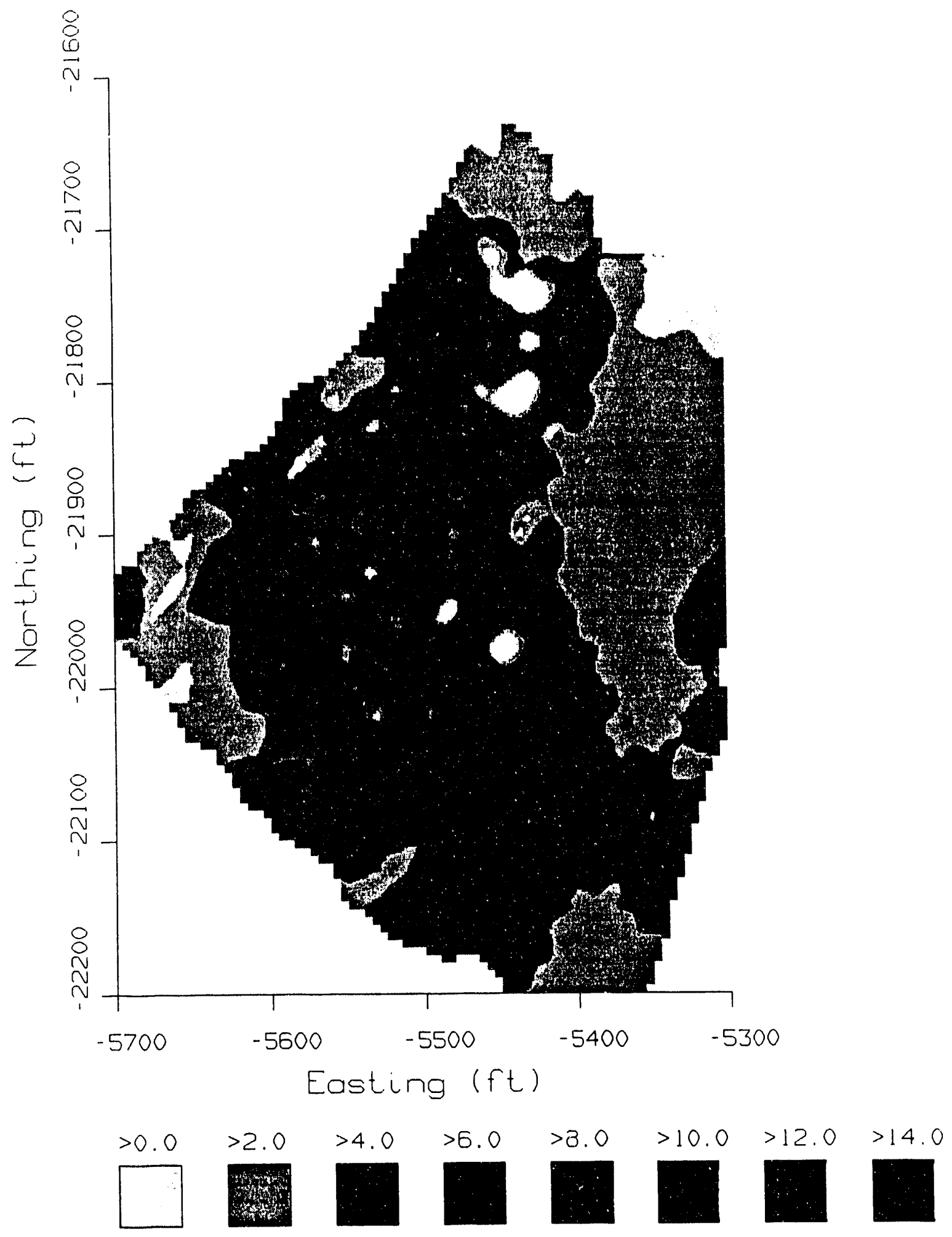

Fig. 10. Gray-scale contours of the quadrature data based on the northeast-southwest profiles. 


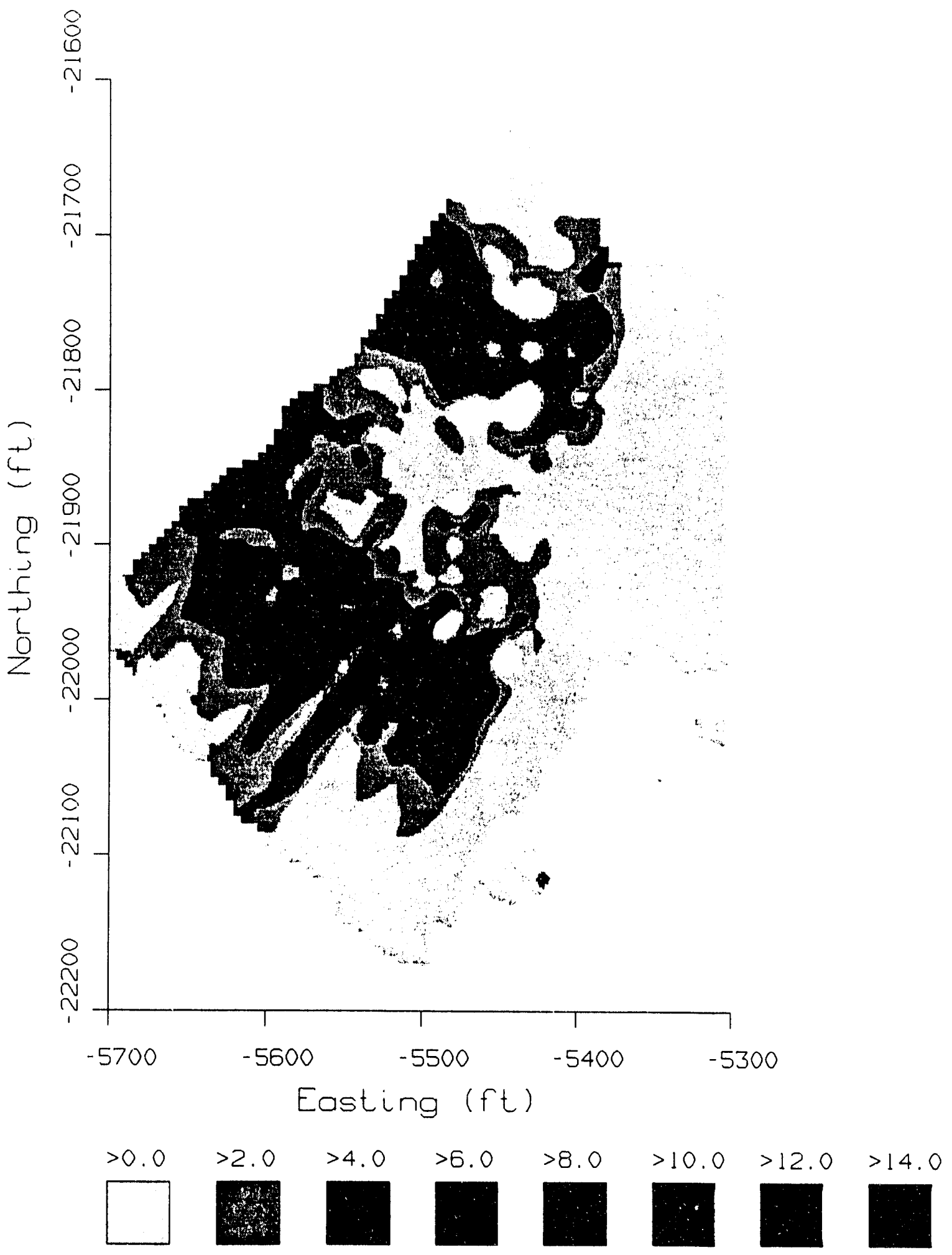

Fig. 11. Gray-scale contours of the inphase data based on the northeast-southwest profiles. 


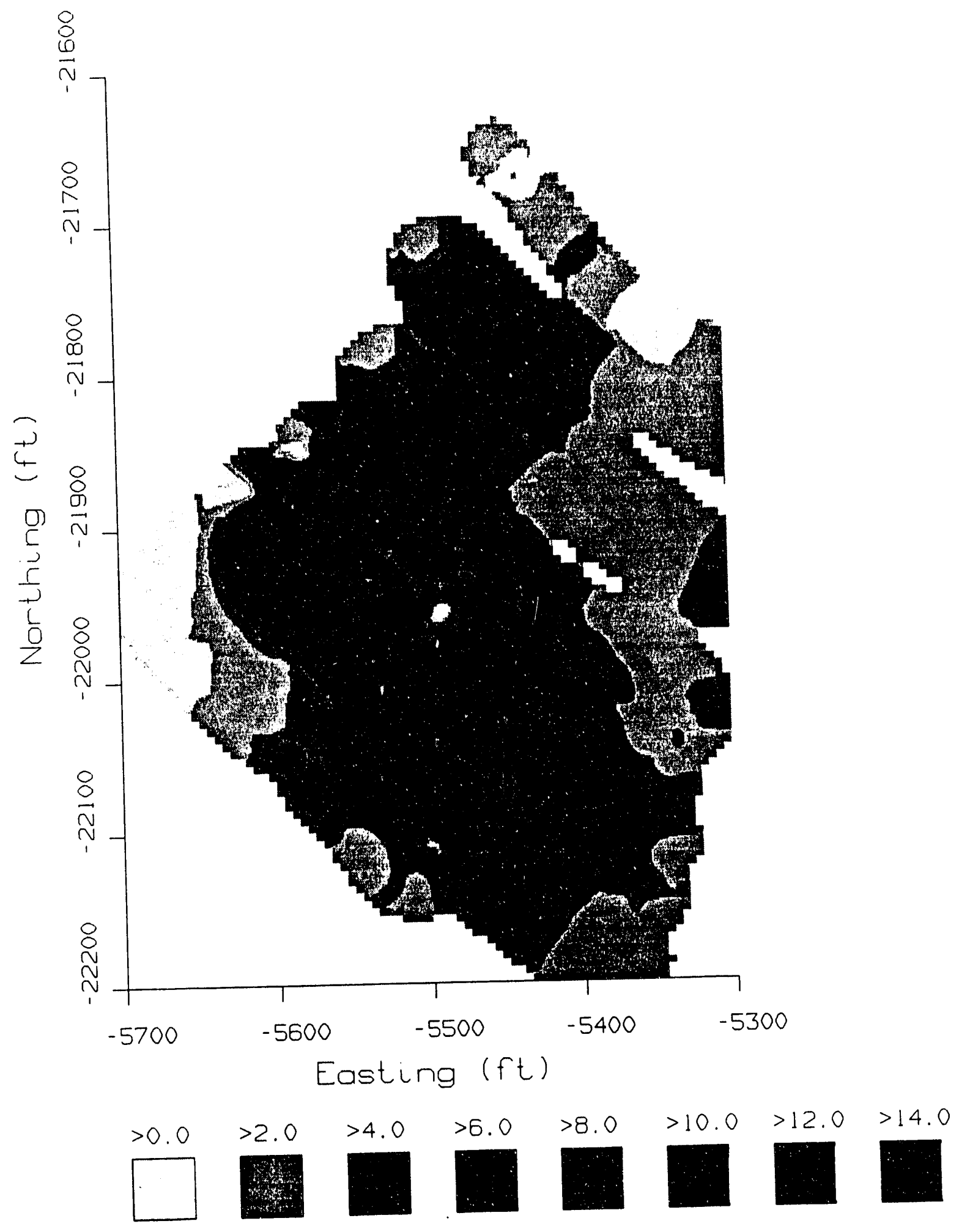

Fig. 12. Gray-scale contours of the quadrature data based on the northwest-southeast profiles. 


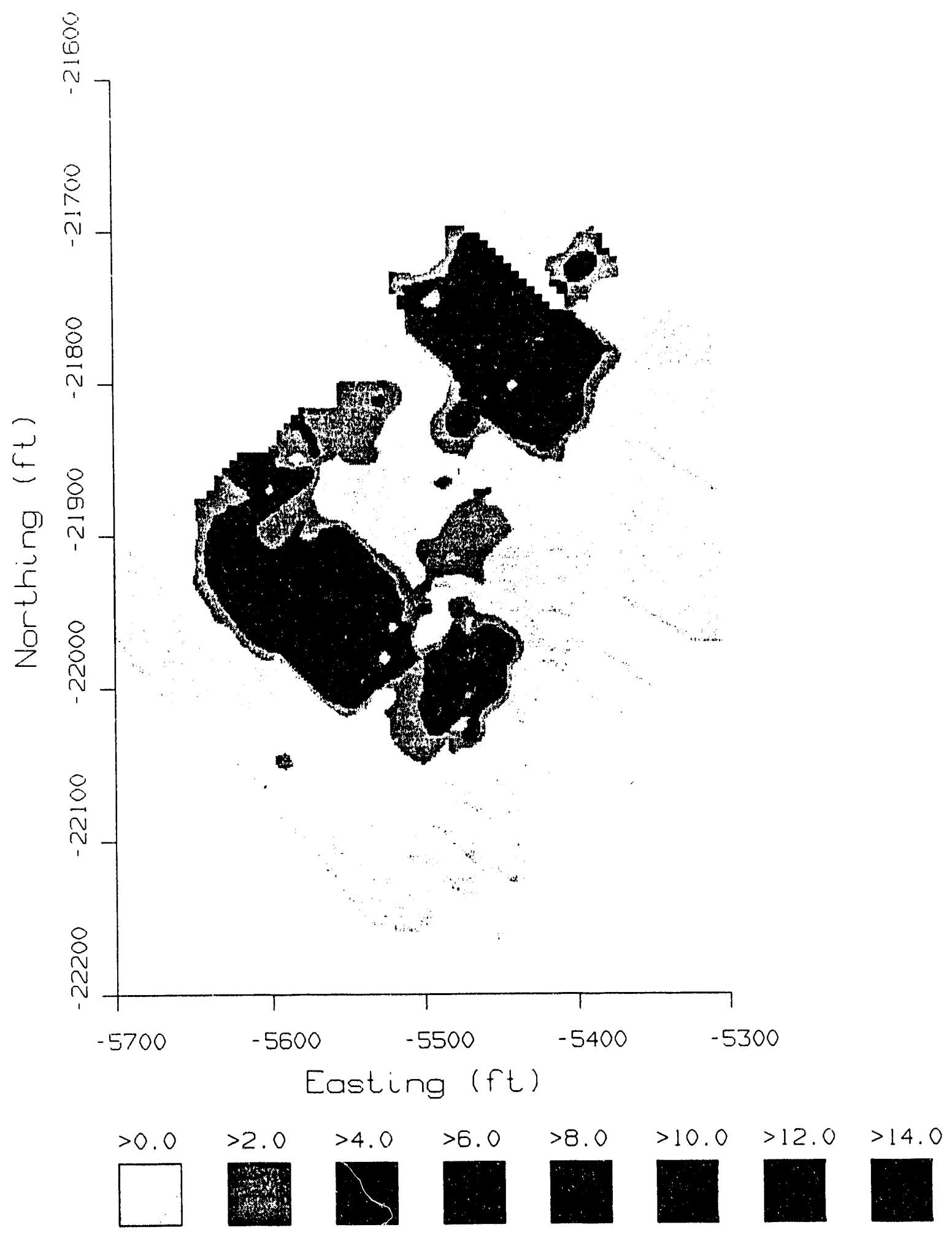

Fig. 13. Gray-scale contours of the inphase data based on the northwest-southeast profiles. 


\section{CONCLUSIONS}

\subsection{BURIAL GROUND BOUNDARIES AND WELL DRILLING}

The quadrature data from the northwest-southeast traverses appear to best show the overall boundaries of the burial areas (Fig. 12). When the contours are superimposed on the site map (Fig. 14), the boundaries of the terrain conductivity anomalies and the burial plan agree well, with the exception that the anomalies extend to the northwest beyond the diagrammed waste pit boundaries and into the woods where we were unable to survey. The boundary between the anomalous area (tightly clustered contour lines) and background is abrupt, and it should be possible to drill monitoring wells safely within 10-20 ft of the waste areas. Attempting to drill wells between the trenches would be too ambitious, however, as the trench separation is too small to resolve accurately with the EM31.

It is possible for a waste canister to go undetected if (1) the waste is buried below the detection limit of the instrument, (2) the canister is too small to detect, or (3) the survey lines are spaced too widely and canisters between the survey lines are beyond the sensor range. The records indicate that the waste at the K1070A burial ground was not buried deeply, so the 3-m depth detection limit of the EM31 should be adequate. Because the waste was buried in trenches, the cumulative anomaly of many small canisters should be easily detectable. Finally, we used the USRADS automatic locating and data logging system to enable us to collect terrain conductivity data on tightly spaced survey lines with average separations between measurement points along line of abnut $0.5 \mathrm{~m}$ with line separations of about $5-8 \mathrm{~m}$. In addition, the two perpendicular sets of traverses, the first running northwest-southeast and the second running northeast-southwest, provide double coverage of the entire site, reducing the chance of missing a canister.

Nonetheless, although the EM31 data delineate the regions where it would be inadvisable to drill, the data do not guarantee that a region is free of drilling hazards. If the hazard is not electrically conductive, is deeper than about $3 \mathrm{~m}$, or is small and was buried away from the main disposal area, the EM31-based apparent conductivity map will not show any corresponding anomaly. Appropriate health and safety procedures are advisable if wells are to be drilled close to the waste areas.

\subsection{SUBSEQUENT GEOPHYSICAL SURVEYS}

Any subsequent geophysical survey will almost certainly consist of either a series of linear traverses of the site or a much larger grid spacing. By taking advantage of the extremely tight coverage of the EM31/USRADS data, future surveys can be planned. Ground-penetrating radar data, for example, are generally collected along linear profiles. Radar data could be used to obtain a better definition of the individual trench boundaries than can be obtained from EM31 data alone to guide placement of wells between trenches. 
SCALE : = : BO

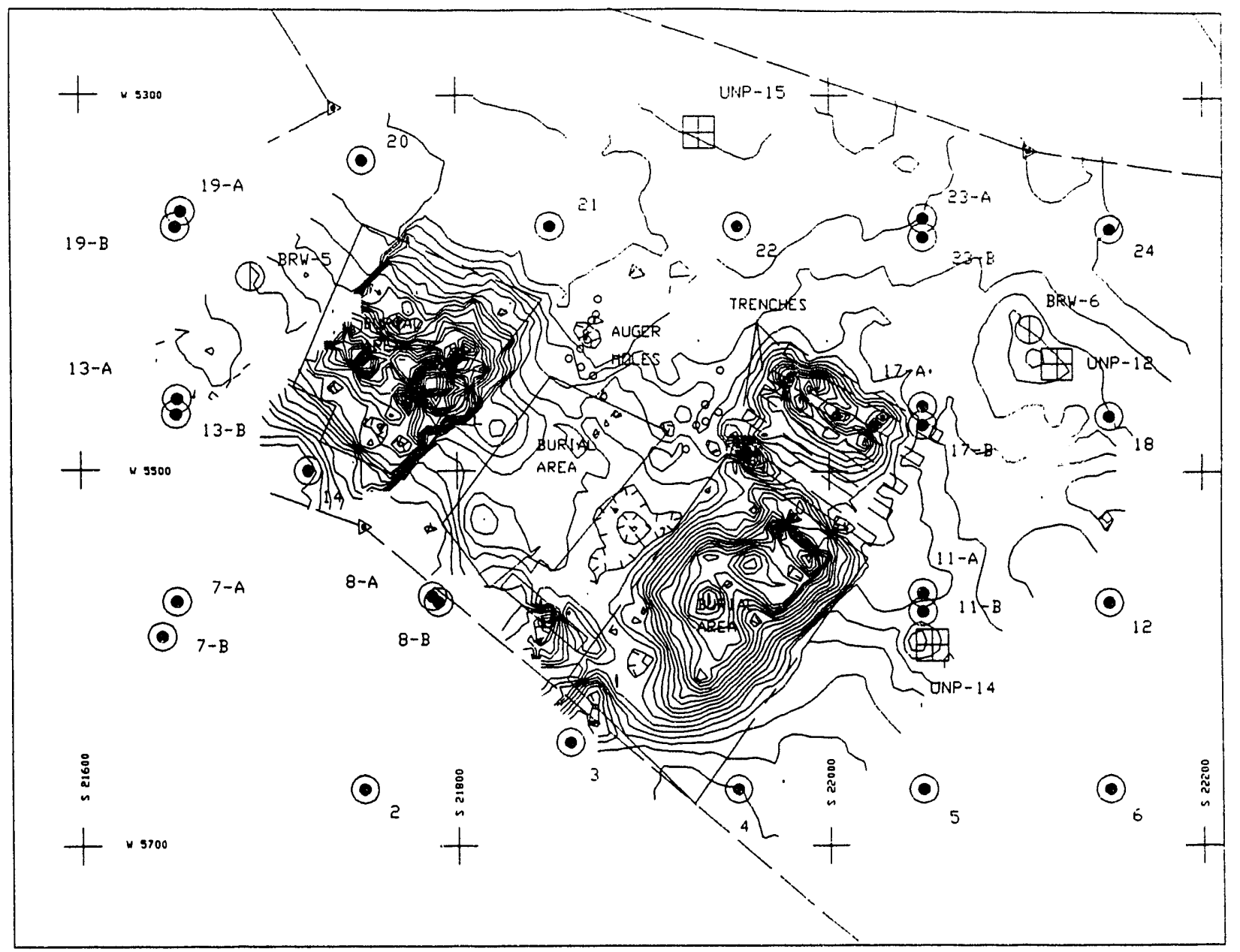

- soil sampling puint

$\exists$ Piezameter

(1) BEDROCK WELL

Fig. 14. The contours of the quadrature data based on the northwest-southeast profiles (Fig. 12) superimposed on the site map. 


\section{REFERENCES}

Frischknecht, F. C., V. F. Labson, B. R. Spies, and W. L. Anderson. 1991. Profiling methods using small sources. In Electromagnetic Methods in Applied Geophysics. vol. 2A. M. N. Nabighian (ed.). Society of Exploration Geophysicists, Tulsa, Oklahoma. pp. 105-270.

Geonics Limited. 1984. Operating Manual for the EM31-D Non-Contacting Terrain Conductivity Meter. Geonics Limited, Mississauga, Ontario, Canada. 60 pp.

McNeill, J. D. 1980a. Electrical Conductivity of Soil and Rocks. Technical Note TN-5. Geonics Limited, Mississauga, Ontario, Canada. 22 pp.

McNeill, J. D. 1980b. Electromagnetic Terrain Conductivity Measurement at Low Induction Numbers. Technical Note TN-6. Geonics Limited, Mississauga, Ontario, Canada. 15 pp.

McNeill, J. D. 1983. Use of EM31 Inphase Information. Technical Note TN-11. Geonics Limited, Mississauga, Ontario, Canada. 2 pp.

Nyquist, J. E., and M. S. Blair. 1991. A geophysical tracking and data logging system: Description and case history. Geophysics 56(7), 1114-1121.

Telford, W. M., L. P. Geldart, and R. E. Sheriff. 1990. Applied Geophysics. 2nd ed. Cambridge University Press, New York. 770 pp. 


\section{Appendix}

\section{EXPLANATION OF DATA PROVIDED ON MAGNETIC MEDIA}

Available from the Environmental Restoration Document Management Center at the Oak Ridge K-25 Site are two IBM PC-compatible floppy disks, one containing the raw data for all the blocks and the other containing the AutoCAD drawing files used to produce some of the figures.

\section{DISK 1-EM31 DATA}

The data are in four columns: $x$, easting in Idaho Nuclear Engineering Laboratory grid coordinates (ft); $y$, northing in K-25 Site grid coordinates $(\mathrm{ft})$; the EM31 quadrature response at that point (mmhos/m); and the EM31 inphase response at that point (relative values only, see text). This format is compatible with most spreadsheet, database, or contouring software.

\section{Raw Data Files in K-25 Site Coordinates}

These are ASCII files set up in 4 columns and 4975 rows. Each row is a measurement (easting, northing, quadrature, inphase).

$\begin{array}{lllll}\text { A1070A } & \text { DAT } & 53879 & 11-06-91 & 4: 35 a \\ \text { A1070C } & \text { DAT } & 90257 & 11-06-91 & 5: 02 a \\ \text { A1070E } & \text { DAT } & 69789 & 11-06-91 & 5: 04 a\end{array}$

Raw Data Files in Same Format as Above but with the EM31 Turned Off

Because the EM31 was turned off, the last two columns contain garbage. These files just contain coordinate data collected when we walked along or around objects of interest such as wells, roads, and auger holes.

$\begin{array}{lllll}\text { A1070B } & \text { DAT } & 7783 & 11-06-91 & 4: 36 a \\ \text { A1070D } & \text { DAT } & 8041 & 11-06-91 & 5: 03 a \\ \text { A1070F } & \text { DAT } & 18533 & 11-06-91 & 5: 05 a\end{array}$

Blocks A, C, and E Combined

ALL $\quad$ DAT $\quad 184075 \quad 11-13-91 \quad 1: 37 a$


Grid Fles Using the Surfer Program (Binary Format)

$\begin{array}{llllll}\text { NSALLQ } & \text { GRD } & 39260 & 11-19-91 & 11: 01 \mathrm{a} & \text { NE-SW profiles, quadrature data } \\ \text { NSALLP } & \text { GRD } & 39260 & 11-19-91 & 11: 12 \mathrm{a} & \text { NE-SW profiles, inphase data } \\ \text { EWALLQ } & \text { GRD } & 39260 & 11-19-91 & 11: 24 a & \text { NW-SE profiles, quadrature data } \\ \text { EWALLP } & \text { GRD } & 39260 & 11-19-91 & 11: 35 a & \text { NW-SE profiles, inphase data }\end{array}$

DISK 2-DRAWING FILES

AutoCAD Drawing Files for the EM31/USRADS Survey

The file listed below contains the track map showing the locations of all the measurements with an " $x$ " at each measurement point. The northeast-southwest and northwest-southeast profiles are in separate layers from the base map showing the weil locations, etc.

KWAGPOST DWG $856895 \quad 11-24-91 \quad 11: 14 p$

The file listed below contains the quadrature contours based on the northwest-southeast profiles in a separate layer from the base map and the track map outlining the cultural features mapped using USRADS in another layer.

KWAGCON DWG $263248 \quad 11-25-91 \quad 2: 25 a$ 
$\varnothing$
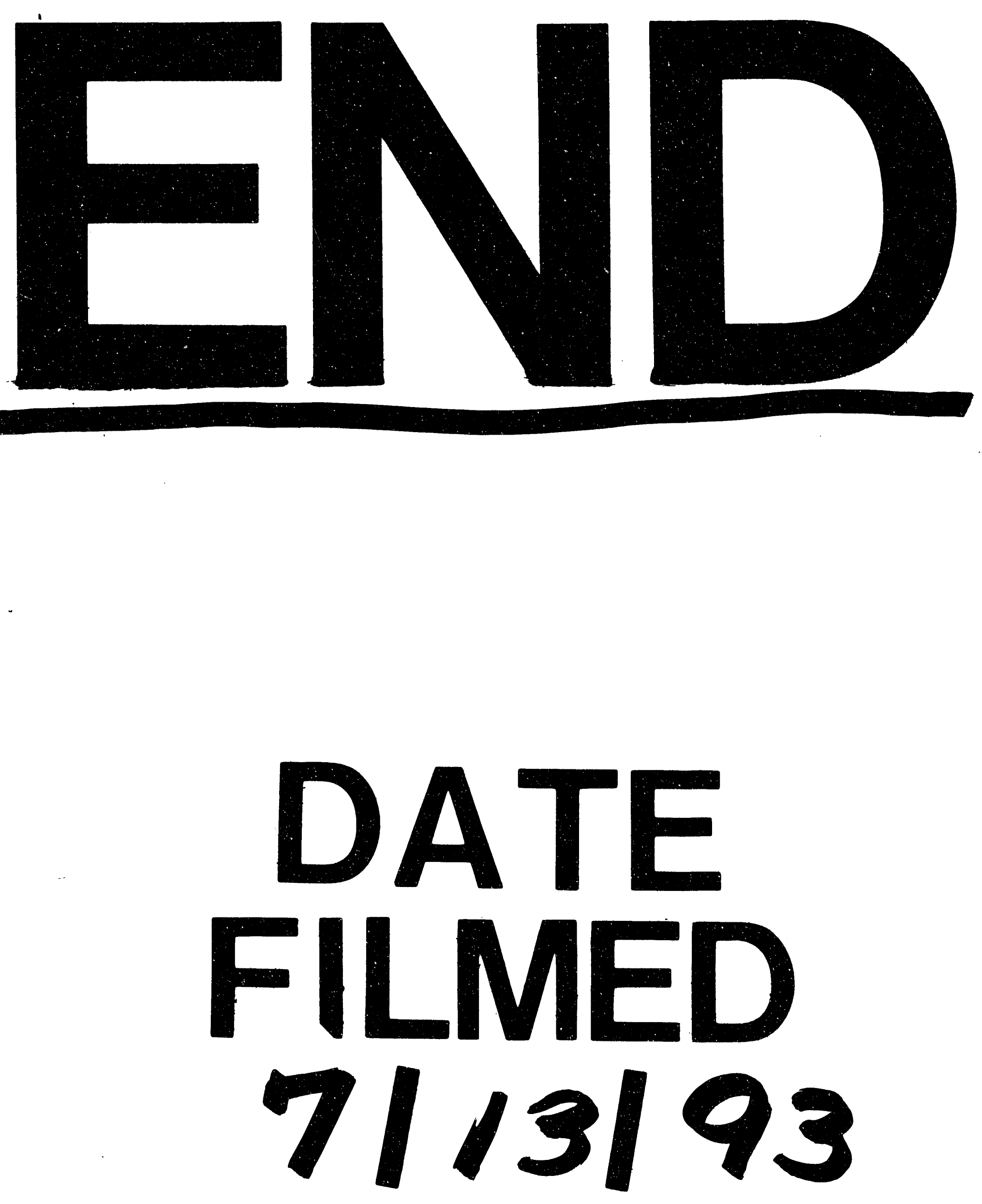
.

1 